\title{
The Genomic Organization and Polymorphism Analysis of the Human Niemann-Pick C1 Gene
}

\author{
J ill A. Morris, ${ }^{* 1}$ Dana Zhang,* Katherine G. Coleman,* J ames Nagle,* \\ Peter G. Pentchev,* and Eugene D. Carstea† \\ *National Institute of Neurological Disorders and Stroke, National Institutes of Health (NIH), Bethesda, Maryland 20892; \\ and †Saccomanno Research Institute, St. Mary's Hospital and Medical Center, Grand J unction, Colorado 81502
}

Niemann-Pick C (NP-C) is a fatal autosomal recessive storage disorder characterized by progressive neurodegeneration and variable hepatosplenomegaly. At the cellular level, cells derived from an affected individual accumulate unesterified cholesterol in lysosomes when cultured with low-density lipoprotein. The NP-C gene was identified at 18q11. The transcript is $4.9 \mathrm{~kb}$ encoding a 1278-amino-acid protein. We have defined the genomic structure of NPC1 along with the 5 ' flanking sequence. The NPC1 gene spans greater than $\mathbf{4 7} \mathbf{~ k b}$ and contains $\mathbf{2 5}$ exons. Exons range in size from 74 to 788 bp with introns ranging in size from 0.097 to $7 \mathrm{~kb}$. All intron/exon boundaries follow the GT/AG rule. The 5' flanking sequence has a C pG island containing multiple Sp1 sites indicative of a promoter region. The CpG island is located in the $5^{\prime}$ flanking sequence, exon 1 and the $5^{\prime}$ end of intron 1 . We have also identified multiple single nucleotide polymorphisms in the coding and intronic sequences. ๑ 1999 Academic Press

Niemann-Pick C disease (NP-C) is a neurovisceral lipid storage disorder (see reviews, $1-3$ ). It has an estimated incidence as high as 1:150,000 (1). The age at which symptoms clearly appear can vary from infancy to late adulthood with the majority of patients presenting in childhood (1). The neurological profile includes progressive ataxia, dysphagia, dystonia, dementia, and the hallmark feature supranuclear vertical gaze palsy (1).

When NP-C fibroblasts are cultured with lowdensity lipoprotein (LDL), extensive unesterified cho-

\footnotetext{
${ }^{1}$ To whom correspondence should be addressed at present address at Merck Research Laboratories, Department of Human Genetics, WP26A-3000, P.O. Box 4, West Point, PA 19486. Fax: (215) 6522075. E-mail: jill_morris@merck.com.

Accession numbers: AF 157365, AF 157366, AF 157367, AF 157368, AF 157369, AF 157370, AF 157371, AF 157372, AF 157373, AF 157374, AF 157375, AF 157376, AF 157377, AF 157378, and AF 157379.
}

lesterol accumulates in lysosomes $(2,4-7)$. This anomalous metabolic sequestration of cholesterol has been shown to cause delays in the homeostatic responses that normally regulate cellular chol esterol levels $(2,5)$. Cytochemical and biochemical tests that monitor this cholesterol lipidodic state have in the past provided the only means of establishing a laboratory diagnosis of NP-C $(1,2,5)$. Such cellular testing has proven difficult to interpret in cell lines that display only partial phenotypic penetrance particularly in prenatal testing and does not exist for carrier testing (8).

There are two separate disease gene loci responsible for NP-C disease. The NPC1 gene is mutated in the majority of documented cases ( $95 \%$ ) and an unidentified second loci, NPC2, is estimated to account for $5 \%$ of cases $(9-11)$. The human NPC1 gene is located on $18 q 11$ and has a transcript of $4.9 \mathrm{~kb}$ encoding a pre sumed protein of 1278 amino acids. Human NPC1 has 13-16 putative transmembrane domains, 12 of which have high homology to Patched, a protein involved with the Sonic hedgehog signaling pathway $(9,10,12)$. Included in the twelve are five transmembrane regions with a putative sterol-sensing domains (SSD) similar to those found in SREBP Cleavage Activating Protein, SCAP, and HMG-CoA Reductase $(9,13,14)$. The NPC1 protein also has an endoplasmic reticulum targeting signal sequence, a leucine zipper motif in an interspecies conserved region, and a lysosomal targeting motif.

As could be expected, the successful identification of the NPCl gene $(9,10)$ has al ready expedited the laboratory diagnosis of this disorder in French Acadian patients of Nova Scotia (15). A common mutation has been shown to be linked to a large number of individuals in a demographically restricted location (15). However, the initial observation of multiple separate private NPCl mutations in the general population has been found by several other investigators (personal communications from Dr. Marie Vanier (INSERM U.), Dr. Kosaku Ohno (Tottori U.) and Dr. Peter Bauer (U. Rostock) in March, 1999) (9). Thus the currently avail- 


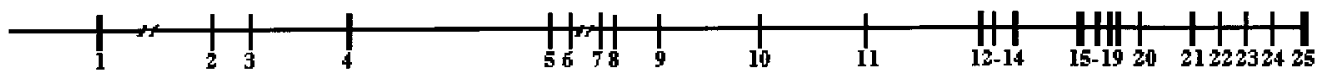

- $=1$ kh

FIG. 1. The genomic structure of the NPCl gene. The intron sizes are to scale and the numbers bel ow the black boxes indicate the exon number.

able technique of RT-PCR based NPC1 mRNA analyses has its limitations in a wide spread survey of hundreds of unrelated families. The successful characterization of the full human genomic NPC1 organization and its intron/exon sequence intervals as reported here not only expands further studies of the gene but also provides the opportunity of expediting these mutational analyses through a DNA based PCR strategy.

\section{MATERIALS AND METHODS}

Characterization of intron sizes and the intron/ exon boundaries through sequencing of genomic clones and through PCR amplification from genomic DNA. The bacterial artificial chromosome (BAC) clone 108N2 (Research Genetics) was previously defined to contain NPC1 genomic sequence (9). Pstl or BamHI restriction enzyme digested genomic fragments from 108N2 were subcloned into pUC18 (Life Technologies). Subclones were transformed into $\mathrm{DH} 5 \alpha$ bacteria (Life Technologies) and isolated colonies were grown in LuriaBertani (LB) with ampicillin at $37^{\circ} \mathrm{C}$ from which $15 \%$ glycerol stocks were made. Glycerol stocks of individual subclones were arrayed into three 96-well plates. The 96-well glycerol stocks were replica plated onto nylon filters. The filters were laid onto LB agar plates containing ampicillin and placed at $37^{\circ} \mathrm{C}$ overnight. The colonies on the filters were lysed and hybridized against portions of the NPC1 CDNA by standard techniques (16). DNA was isolated from positive colonies using the Wizard kit from Promega. The DNA was sequenced (Applied Biosystems). Seqwright also sequenced portions of the BAC $108 \mathrm{~N} 2$ by shotgun sequencing.

Many of the intron/exon boundaries and the intron sizes were determined by long range PCR amplification of genomic DNA from unaffected individuals using NPC1 specific primer (Clontech, Boehringer-Mannheim). PCR products were subcloned using the TA Cloning vector (Invitrogen) and sequenced multiple times in both directions across the intron/exon boundaries. Introns 5, 7, 12, 13, 15-19, 22, and 23 were completely sequenced. The sizes of the remaining introns were determined by gel electrophoresis.

Intron/exon boundaries were defined by comparing the genomic NPC1 sequence versus the NPC1 CDNA sequence using the MacVector program, Assemblign (Oxford Molecular). Consensus sequences were aligned using Sequencher 3.0 (Gene Codes Co.). All boundaries were sequenced with multiple reads in both directions and were sequenced at least $100 \mathrm{bp}$ into the intron. Sequences were submitted to GenBank and the accession numbers are indicated (Table 1).

Characterization of the transcription start site. 5' RACE (rapid amplification of CDNA ends) was done according to manufacturer's instruction (Life Technologies) on RNA from fibroblasts obtained from unaffected individuals with a NPC1 specific primer. Secondly, the $5^{\prime}$ end of the NPC1 CDNA was PCR amplified from Marathon ready CDNA libraries from ovary and fetal tissue (Clontech). Products were analyzed by gel el ectrophoresis. The largest products were gel purified and sequenced (Applied Biosystems).

Characterization of the $5^{\prime}$ flanking sequence By hybridization, two 108N2 BAC subclones were identified which contained the 5' flanking sequence. The subclones were sequenced multiple times in both directions. The $5^{\prime}$ flanking sequence was analyzed for CpG islands using Grail version 1.3 (17). Matl nspector was used to identify potential transcription factor binding sites (18). Binding sites listed have a core similarity of 1.00 and matrix similarity of greater than 0.900 .

Polymorphism analysis of the NPC1 genomic sequence Single nucleotide polymorphisms (SNPs) were identified by comparing PCR amplified NPC1 sequences and BAC 108N2 sequences (described above) with that of the published NPC1 CDNA sequence (AF 002020) (9). Polymorphisms in the intronic sequences were defined by comparing NPC1 sequences amplified from the DNA of unaffected individuals. The recommendations of the Nomenclature Working Group were used to name the polymorphisms (19) (Table 2).

\section{RESULTS AND DISCUSSION}

The structure of the NPCl gene was characterized through both the sequencing of PCR products amplified from genomic DNA with NPCl CDNA specific primers and through the sequencing of subcloned $B A C$ DNA. The BAC clone 108N2 was defined in the NPC1 critical interval sequence by the genetic marker D18S75E and was shown to contain NPC1 genomic sequence (9). We have found $108 \mathrm{~N} 2$ to contain the entire genomic structure for the NPCl gene.

The entire genomic structure of the NPCl gene is greater than $47 \mathrm{~kb}$ (Fig. 1). There are 25 exons which range in size from $74 \mathrm{bp}$ (exon 7) to $788 \mathrm{bp}$ (exon 25) (Table 1). Introns range in size from 97 bp (intron 15) to $7 \mathrm{~kb}$ (intron 4). We were unable to amplify across introns 1 and 6 to determine their exact sizes. Sequence information for introns 1 and 6 is from BAC subclones. The complete sequences of introns $5,7,12$, $13,15-19,22$, and 23 were determined. Introns 14 and 17 vary in size by a few base pairs due to polymorphisms in repeats of Ts. The rest of the boundaries were sequenced at least $100 \mathrm{bp}$ into the intron. All boundaries were analyzed with multiple sequence reads in both directions. The intron/exon boundaries all follow the GT/AG rule, GT is the splice donor and AG is the splice acceptor (20).

To define the transcription start site of NPC1, 5' RACE was performed on RNA from fibroblasts obtained from unaffected individuals with a primer from the $5^{\prime}$ end of the NPC1 CDNA. In addition, PCR amplification of the $5^{\prime}$ end of the NPC1 CDNA was also done using Marathon ready cDNA libraries. The DNA sequence of these products did not result in any transcripts with sequences longer than the previously published transcription start site at -121 bp from the ATG 


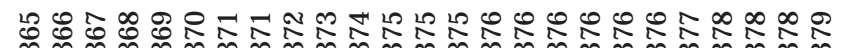

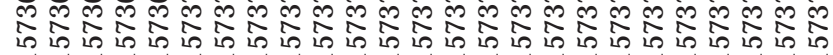

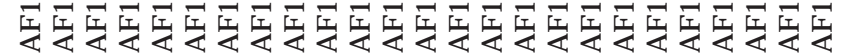

○

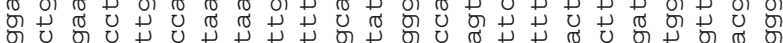

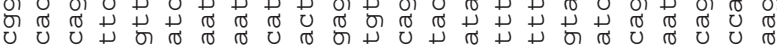
舟 ర్d

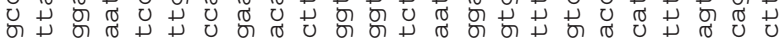

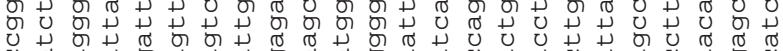

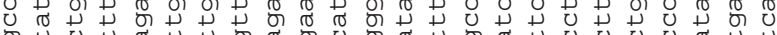

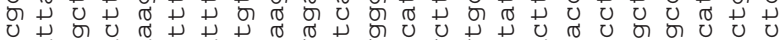

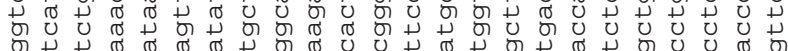

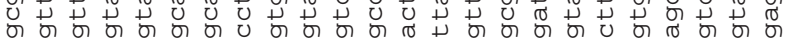

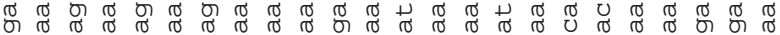

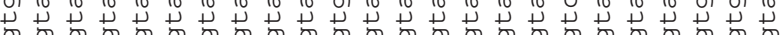

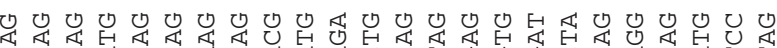

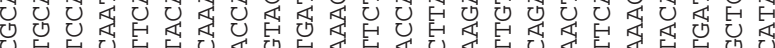

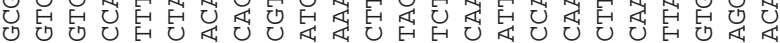

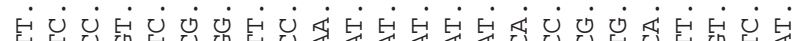

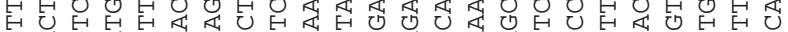

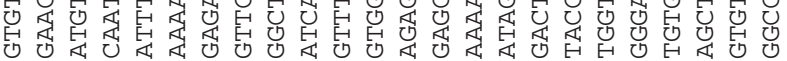

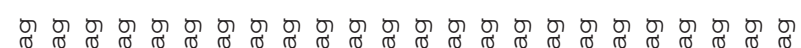

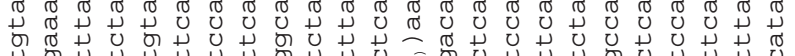
$\begin{array}{llllllll}0 & 0 \\ 0 & 0\end{array}$

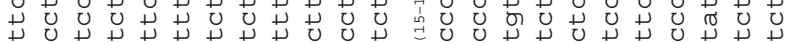

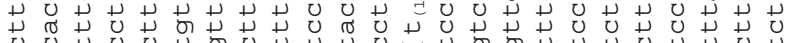
O

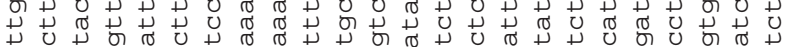

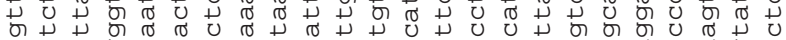

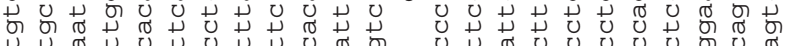

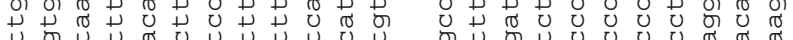

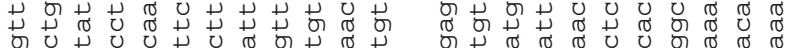

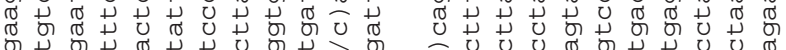

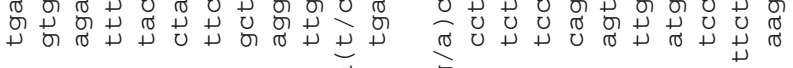

\begin{tabular}{ccc}
$\pi$ & क्षे \\
\hline & 0
\end{tabular}

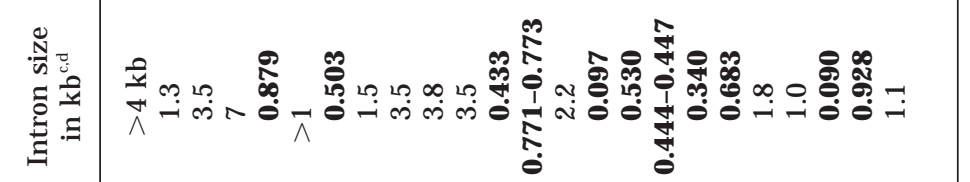

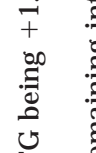

安

过

ब

至

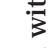

8.

औ 3

흔 은 


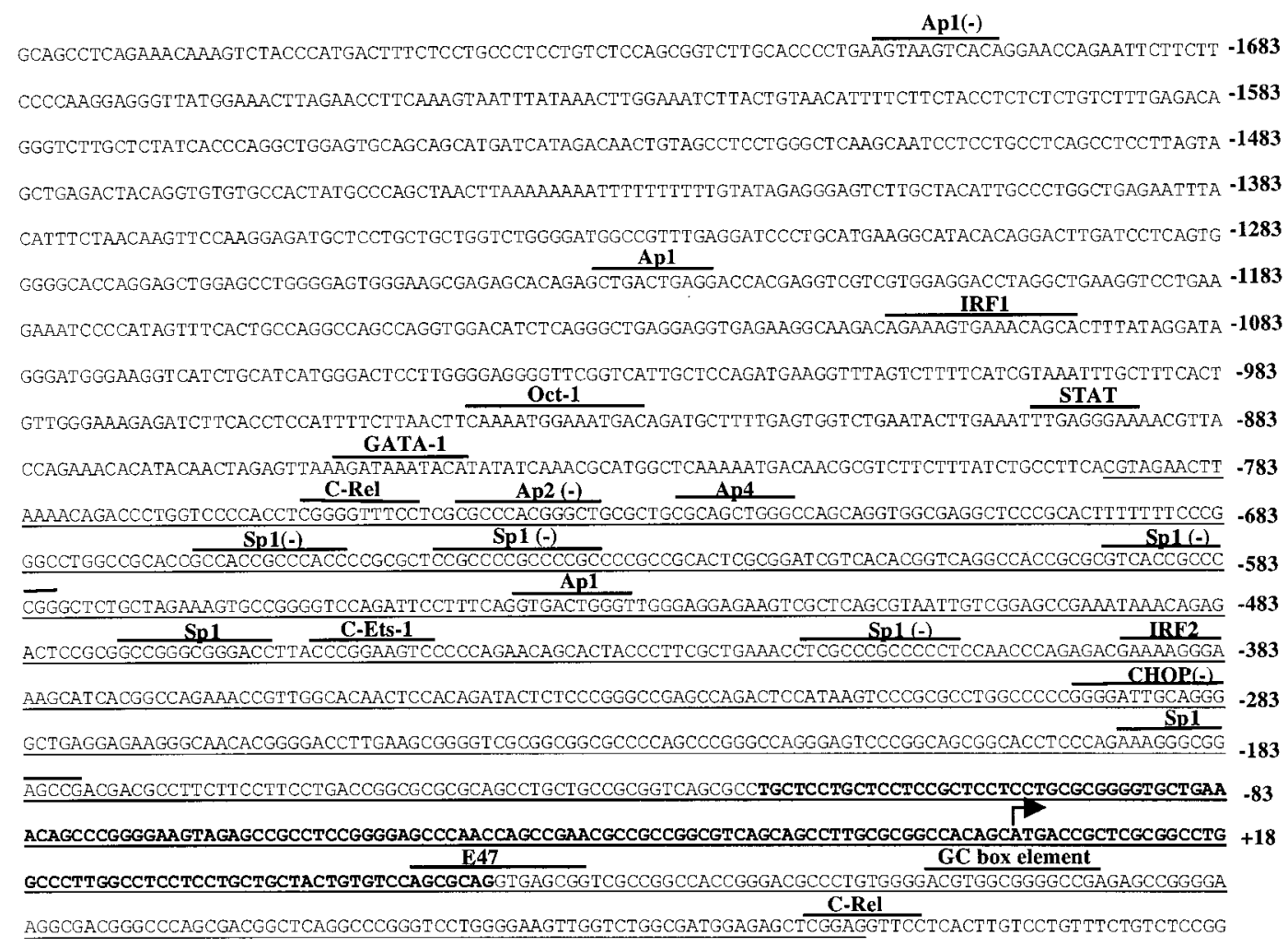

CCACGCTCTCTTTCCTGTGGTCTGGAAGAGGGTGGCAGTGGGGCTTGGGTGACCTGTTCTGAGCT TGTTCCATCTGTGGT CACCTAATTTCTCTGTGTA

FIG. 2. The $5^{\prime}$ flanking sequence of $N P C 1$ gene. The bold type indicates transcribed sequence. The underlined sequence is the CpG island determined by Grail version 1.3 (17). Potential transcription factor binding sites were determined by Matl nspector (core similarity of 1.00 and matrix similarity of $>0.900$ ) (18). Binding sites with a $(-)$ are in the antisense direction. The complete 3-kb sequence is deposited in GenBank (AF 157365).

(the $A$ being nucleotide +1 ) (9). This data suggests that the genomic sequence upstream of the transcription start site $(-121)$ contains the NPCl promoter region.

Two genomic subclones from the BAC 108N2 contained the $5^{\prime}$ flanking sequence of the NPC1 gene (Fig. 2). One clone (BamHI G5) contained 3 kb of $5^{\prime}$ flanking sequence along with exon 1 and the $5^{\prime}$ end of intron 1 . The 5' flanking region does not contain a TATA sequence, but it did contain a GC rich sequence with six Spl sites indicative of the promoter of the gene (21-23). CpG island analysis using Grail yiel ded a CpG score of 0.848 with a GC composition of $69.7 \%$ on a $980-b p$ region of the $5^{\prime}$ flanking sequence (17). CpG islands are defined by a $\mathrm{CpG}$ score greater than 0.6 with a percentage GC of greater than $50 \%$ (21). The CpG island extended from nucleotide -792 into the $5^{\prime}$ flanking sequence ( $A$ of ATG being +1 ) through exon 1 into the $5^{\prime}$ end of intron 1 . The $5^{\prime}$ end of intron one has a GC rich region with $80 \%$ GC composition compared to all the other 5 ' intronic sequences in the NPC1 gene which have a GC content of $60 \%$ or less. CpG islands have been defined to be at the transcription start site of many housekeeping genes $(21,22)$. Their open conformations are believed to allow the binding of transcrip- tion factors to promoter regions $(22,24)$. Matl nspector was used to define multiple potential transcription factor binding sites (18) (Fig. 2). Further experiments need to be performed to define the biological relevance of these putative binding sites.

Polymorphisms were identified in the coding and intronic sequences of the NPC1 gene (Table 2). Ten SNPs were identified in the coding sequence by comparing the published NPC1 cDNA sequence (AF 002020) with sequences amplified from genomic DNA and by RT-PCR (Table 2a). This sequence amplification was performed on DNA and RNA from unaffected individuals. Three of the SNPs (at nucleotides 1755, 2226, and 2793) did not change the encoded amino acid. The rest of the SNPs resulted in relatively conservative changes. At nucleotide 644 , there is a SNP that results in an arginine instead of a histidine, which are both basic amino acids. At nucleotide 998, a SNP was identified in unaffected individuals that re sults in a glycine being an aspartic acid. The mouse $\mathrm{N} \mathrm{pcl}$ ortholog also has an aspartic acid at this position. In addition, at nucleotide 2572, an A > G polymorphism results in an isoleucine being a valine. In the mouse Npcl ortholog, there is an isoleucine at this 
TABLE 2a

Single Nucleotide Polymorphisms I dentified in the NPC1 Coding Sequence

\begin{tabular}{|c|c|c|c|c|c|}
\hline \multirow[b]{2}{*}{ Nucleotide $e^{a, b}$} & \multirow[b]{2}{*}{ Amino acid change } & \multirow{2}{*}{$\begin{array}{l}\text { Region in the } \\
\text { NPCl protein }\end{array}$} & \multicolumn{3}{|c|}{ Amino acids in NPC1 orthologs ${ }^{c}$} \\
\hline & & & Mouse & Yeast & Worm \\
\hline$c 644 A>G$ & $215 \mathrm{His} \rightarrow \mathrm{Arg}$ & - & Leu & Glu & Thr \\
\hline$C 998 \mathrm{G}>\mathrm{A}$ & 333 Gly $\rightarrow$ Asp & - & Asp & Gly & Asn \\
\hline C1415T > C & 472 Leu $\rightarrow$ Pro & - & Leu & Thr & Met \\
\hline c1755A > G & 585 Lys $\rightarrow$ Lys & - & Lys & Glu & Lys \\
\hline$c 1926 C>$ G & $642 \mathrm{lle} \rightarrow$ Met & Transmembrane & Ile & - & Tyr \\
\hline $\mathrm{c} 2226 \mathrm{G}>\mathrm{A}$ & $742 \mathrm{Glu} \rightarrow$ Glu & - & Glu & Gln & Cys \\
\hline c2270T > C & $757 \mathrm{Val} \rightarrow$ Ala & Transmembrane & Val & Val & Ile \\
\hline$c 2572 A>C G$ & $858 \mathrm{Ile} \rightarrow$ Val & Transmembrane & Ile & Phe & Val \\
\hline$c 2793 C>T$ & 931 Asn $\rightarrow$ Asn & - & Thr & $\mathrm{His}$ & Glu \\
\hline c3659T > C & $1220 \mathrm{lle} \rightarrow \mathrm{Thr}$ & - & Ile & Ile & Ile \\
\hline
\end{tabular}

${ }^{a} \mathrm{c}$ indicates that the nucleotide position corresponds to the NPC1 CDNA sequence with the A of ATG being +1 .

${ }^{\mathrm{b}}$ All polymorphisms are named according to the recommendations of the Nomenclature Working Group (19).

' The orthologous amino acids from mouse (AF 003348), yeast (Saccharomyces cerevisiae, L pallp, U33335), and worm (Caenorhabditis elegans, F 02E 8p, U53340) NPC1 proteins were identified by ClustalW Alignments (MacVector).

position whereas the worm ortholog has a valine. One of the ten SNPs identified was from RT-PCR product from RNA from unaffected fibroblast. The SNP at nucleotide 1415 was identified in the NPC1 CDNA 1-1 that was previously shown to be an active form of the protein (9). Twenty-six polymorphisms were identified in the intronic sequences of the NPC1 gene (Table 2b). The polymorphisms were identified by comparing amplified sequences from unaffected individuals. $R e-$ cently, there has been a great interest in SNPs for their usefulness in genome scans and association studies (25).

TABLE 2b

Polymorphisms in the Intronic Sequence of the NPC1 Gene

\begin{tabular}{|c|c|c|}
\hline Intron & Polymorphism ${ }^{a, b}$ & Flanking sequences \\
\hline 6 & IVS6 $-47 A>C$ & aaacaacctc $(a / c)$ ctgtgatgaa \\
\hline 10 & IVS10 + 240A > G & gtcgaaggct $(\mathrm{a} / \mathrm{g})$ agtacctttc \\
\hline 11 & IVS11 $+100 G>A$ & aaccaatggc (g/a) gatctgagtt \\
\hline 11 & IVS11 $-178 A>G$ & ccgggaggtg $(\mathrm{a} / \mathrm{g})$ agcttggagt \\
\hline 11 & IVS11 $-22 \mathrm{~T}>\mathrm{C}$ & actaaaata $(t / c)$ aacattttgc \\
\hline 13 & IVS13+ 433A > G & gctgctgtag $(\mathrm{a} / \mathrm{g})$ aggtggtctc \\
\hline 13 & IVS13 $+570 T>A$ & getttccctt $(t / a)$ agtttctcac \\
\hline 13 & IVS13 + 591G >A & ttggtaccta $(g / a)$ ctctgtagtg \\
\hline 13 & IVS13 + 754delT & tgtcgcataa (delt) ttttttttt \\
\hline 13 & IVS13 + $754-755$ delTT & tgtcgcataa (deltt) tttttttttt \\
\hline 14 & IVS14 + 95delT & tgttgcttcc (delt) tettttttt \\
\hline 14 & IVS14 + $121-122$ delTT & tttttttt (deltt) ctctgagacgg \\
\hline 14 & IVS14 - 24G >A & cagaagtgac (g/a) cagagccett \\
\hline 16 & IVS16 $+163 \mathrm{C}>\mathrm{T}$ & atgtttttcc $(c / t)$ gtgagcttt \\
\hline 17 & IVS17 + 15delT & gatgacttcc (delt) ttttttttt \\
\hline 17 & IVS17 + 15 - 17delTTT & gatgacttcc (delttt) ttttttttt \\
\hline 17 & IVS17 $+378 \mathrm{~A}>\mathrm{G}$ & cttattctcc $(\mathrm{a} / \mathrm{g})$ tgatcctcgc \\
\hline 19 & IVS19 + 28T > C & aaatctttcc $(t / c)$ gttttgctga \\
\hline 20 & IVS20 $-158 \mathrm{~T}>\mathrm{C}$ & aaacctttgg $(t / c)$ gttcccttat \\
\hline 21 & IVS21 - 306delT & ttgtttttt (delt)gtgttttttc \\
\hline 21 & IVS21-280G > A & gctgtggaat (g/a) ctctctgtaa \\
\hline 24 & IVS24 + 75T >A & tgaggcattc $(t / a)$ tttcaagtat \\
\hline 24 & IVS24 $-123 C>T$ & gttgtccagg $(c / t)$ tggtctcaag \\
\hline 24 & IVS24 - 89A > G & tcagtcttcc $(\mathrm{a} / \mathrm{g})$ aagtgggatt \\
\hline 24 & IVS24 - 75G >A & tgggattaca (g/a) gcgtgagcca \\
\hline
\end{tabular}

a IVS stands for intervening sequence.

${ }^{\mathrm{b}}$ All polymorphisms are named according to the recommendations of the Nomenclature Working Group (19). 


\section{CONCLUSIONS}

The characterization of the NPC1 genomic structure will be invaluable for mutation detection in this panethnic disorder. It will allow for the diagnosis of patients by genomic DNA as opposed to the currently available methods of RT-PCR or biochemical testing (1, $2,8)$. In this report, we described the 25 intron/exon boundaries. In addition, the putative promoter sequence which contains a $\mathrm{CpG}$ island and multiple Spl sites, indicative of a promoter region, was identified $(22,23)$. Thirty-six polymorphisms were also determined.

\section{ACKNOWLEDGMENTS}

The Ara Parseghian Medical Research Foundation and the National Niemann-Pick Disease Foundation supported this work.

\section{REFERENCES}

1. Patterson, M. C., Vanier, M. T., Suzuki, K., Morris, J. A., Carstea, E. D., Neufeld, E., Blanchett-Mackie, E. J., and Pentchev, P. G. (1997) in The Metabolic and Molecular Bases of Inherited Disease (Scriver, C. R., Sly, W. S., Beaudet, A. L., and Valle, D., Eds.), McGraw Hill, New York.

2. Pentchev, P. G., Brady, R. O., Blanchette-Mackie, E. J ., Vanier, M. T., Carstea, E. D., Parker, C. C., Goldin, E., and Roff, C. F. (1994) Biochim. Biophys. Acta 1225, 235-243.

3. Morris, J. A., and Carstea, E. D. (1998) Mol. Med. Today 4, 525-531.

4. Pentchev, P. G., Comly, M. E., Kruth, H. S., Patel, S., Proestel, M., and Weintroub, H. (1986) J . Biol. Chem. 261, 2772-2777.

5. Pentchev, P. G., Comly, M. E., Kruth, H. S., Tokoro, T., Butler, J., Sokol, J., Filling-Katz, M., Quirk, J. M., Marshall, D. C., Patel, S., Vanier, M. T., and Brady, R. O. (1987) FASEB J . 1, 40- 45.

6. Sokol, J ., Blanchette-Mackie, E. J ., Kruth, H. S., Dwyer, N. K., Amende, L. M., Butler, J. D., Robinson, E., Patel, S., Brady, R. O., Comly, M. E., Vanier, M. T., and Pentchev, P. G. (1988) J . Biol. Chem. 263, 3411-3417.

7. Neufeld, E. B., Wastney, M., Patel, S., Suresh, S., Cooney, A. M., Dwyer, N. K., Roff, C. F., Ohno, K., Morris, J . A., Carstea, E. D., Incardona, J. P., Strauss, J. F., III, Vanier, M. T., Patterson, M. C., Brady, R. O., Pentchev, P. G., and Blanchette-Mackie, E. J . (1999) J . Biol. Chem. 274, 9627-9635.

8. Vanier, T. M., Rodriguez-Lafrasse, C., Rousson, R., Mandon, G., Boue, J., Choiset, A., Peyrat, M., Dumontel, C., J uge M.,
Pentchev, P. G., Revol, A., and Louisot, P. (1992) Am. J . Hum. Genet. 51, 111-122.

9. Carstea, E. D., Morris, J. A., Coleman, K. G., Loftus, S. K., Zhang, D., Cummings, C., Gu, J ., Rosenfeld, M. A., Pavan, W. J ., Krizman, D. B., Nagle, J., Polymeropoulos, M. H., Sturley, S. L., I oannou, Y. A., Higgins, M. E., Comly, M., Cooney, A., Brown, A., Kaneski, C. R., Blanchette-Mackie, E. J ., Dwyer, N. K., Neufeld, E. B., Chang, T., Liscum, L., Strauss, J . F., Ohno, K., Zeigler, M., Carmi, R., Sokol, J., Markie, D., O’Neill, R. R., Van Diggelen, O. P., Elleder, M., Patterson, M. C., Brady, R. O., Vanier, M. T., Pentchev, P. G., and Tagle, D. A. (1997) Science 277, 228-231.

10. Loftus, S. K., Morris, J . A., Carstea, E. D., Gu, J . Z., Cummings, C., Brown, A., Ellison, J., Ohno, K., Rosenfeld, M. A., Tagle, D. A., Pentchev, P. G., and Pavan, W. J . (1997) Science 277, 232-235.

11. Vanier, M. T., Duthel, S., Rodriguez-Lafrasse, C., Pentchev, P., and Carstea, E. D. (1996) Am. J . Hum. Genet. 58, 118-125.

12. J ohnson, R. L., Rothman, A. L., Xie, J., Goodrich, L. V., Bare, J. W., Bonifas, J. M., Quinn, A. G., Myers, R. M., Cox, D. R., Epstein, E. H., J r., and Scott, M. P. (1996) Science 272, 16681671.

13. Chin, D. J ., Gil, G., Russell, D. W., Liscum, L., Luskey, K. L., Basu, S. K., Okayama, H., Berg, P., Goldstein, J . L., and Brown, M. S. (1984) Nature 308, 613- 617.

14. Hua, X., Nohturfft, A., Goldstein, J . L., and Brown, M. S. (1996) Cell 87, 415- 426.

15. Greer, W. L., Riddell, D. C., Gillan, T. L., Girouard, G. S., Sparrow, S. M., Byers, D. M., Dobson, M.J ., and Neumann, P. E. (1998) Am. J . Hum. Genet. 63, 52-54.

16. Sambrook, J., Fritsch, E. F., and Maniatis, T. (1989) Molecular Cloning: A Laboratory Manual, Cold Spring Harbor Laboratory Press, New York.

17. Uberbacher, E. C., Xu, Y., and Mural, R. J. (1996) Methods Enzymol. 266, 259-281.

18. Quandt, K., Frech, K., Karas, H., Wingender, E., and Werner, T. (1995) Nucleic Acids Res. 23, 4878-4884.

19. Antonarakis, S. E., and the Nomenclature Working Group. (1998) Hum. Mut. 11, 1-3.

20. Breathnach, R., and Chambon, P. (1981) in Annual Review of Biochemistry (Snell, E. E., Boyer, P. D., Meister, A., and Richardson, C. C., Eds.), pp. 349-383, Annual Reviews, CA.

21. Gardiner-Garden, M., and Frommer, M. (1987) J . Mol. Biol. 196, 261-282.

22. Larsen, F., Gundersen, G., Lopez, R., and Prydz, H. (1992) Genomics 13, 1095-1107.

23. McKnight, S., and Tijan, R. (1986) Cell 46, 795- 805.

24. Tazi, J., and Bird, A. (1990) Cell 60, 909-920.

25. Collins, F. S., Brooks, L. D., and Chakravarti, A. (1998) Genome Res. 8, 1229-1231. 